\title{
Combined Mitral Valve Replacement and Ravitch Procedures in a Patient with Previous Pneumonectomy: Case Report and Review of the Literature
}

Ilyas Kayacioglu', MD; Ahmet Can Topcu', MD; Kamile Ozeren'1, MD; Yasin Ozden', MD; Ahmet Bolukcu', MD; Mehmet Yildirim², MD

\begin{abstract}
Introduction: Significant anatomical and functional changes occur following pneumonectomy. Mediastinal structures displace toward the side of the resected lung, pulmonary reserve is reduced. Owing to these changes, surgical access to heart and great vessels becomes challenging, and there is increased risk of postoperative pulmonary complications.

Methods: We performed a mitral valve replacement combined with a Ravitch procedure in a young female with previous left
\end{abstract}

pneumonectomy and pectus excavatum.

Results: She was discharged on postoperative day 9 and remains symptom-free 3 months after surgery.

Conclusion: Thorough preoperative evaluation and intensive respiratory physiotherapy are essential before performing cardiac operations on patients with previous pneumonectomy.

Keywords: Chest Wall/surgery. Heart Valve Prosthesis Implantation. Mitral Valve/surgery. Funnel Chest. Pneumonectomy.

\begin{tabular}{ll}
\hline \multicolumn{2}{c}{ Abbreviations, acronyms \& symbols } \\
\hline CABG & $=$ Coronary artery bypass grafting \\
CPB & $=$ Cardiopulmonary bypass \\
CT & $=$ Computed tomography \\
CX & $=$ Circumflex \\
FEV 1 & $=$ Forced expiratory volume in $1^{\text {st }}$ second \\
FVC & $=$ Forced vital capacity \\
LAD & $=$ Left anterior descending \\
LITA & $=$ Left internal thoracic artery \\
MRI & $=$ Magnetic resonance imaging \\
\hline
\end{tabular}

\section{INTRODUCTION}

Significant anatomical and functional changes occur following pneumonectomy. Mediastinal structures displace toward the side of the resected lung, pulmonary reserve is reduced, and the remaining lung compensatorily enlarges and herniates over the midline with elevation of the diaphragm ${ }^{[1,2]}$.
Owing to these changes, surgical access to the heart and great vessels becomes challenging, and there is an increased risk of postoperative pulmonary complications.

\section{CASE REPORT}

A 24-year-old female patient presented to our clinic with dyspnea. She had undergone a left pneumonectomy for advanced and complicated bronchiectasis 10 years ago.

\section{Clinical Findings}

She had marfanoid habitus, pectus excavatum, scoliosis, and a grade 4, pansystolic, high-pitched, blowing murmur best heard at the right sternal border (Figures $1 \mathrm{~A}$ and $\mathrm{B}$ ).

\section{Diagnostic Assessment}

Transthoracic echocardiogram revealed severe mitral regurgitation due to myxomatous mitral valve with bileaflet prolapse and chordal elongation, secondary pulmonary hypertension, and tricuspid regurgitation with a dilated right

No conflict of interest.

Correspondence Address:

Ahmet Can Topcu

Selimiye Mh. Tibbiye Cd., No: 13, Uskudar, Istanbul, Turkey

Zip code: 34668

E-mail: ahmet.topcu@icloud.com
This study was carried out at Dr. Siyami Ersek Thoracic and Cardiovascular Surgery Training and Research Hospital, Istanbul, Turkey.
Article received on February 23rd 2018. Article accepted on June $20^{\text {th }}, 2018$. 


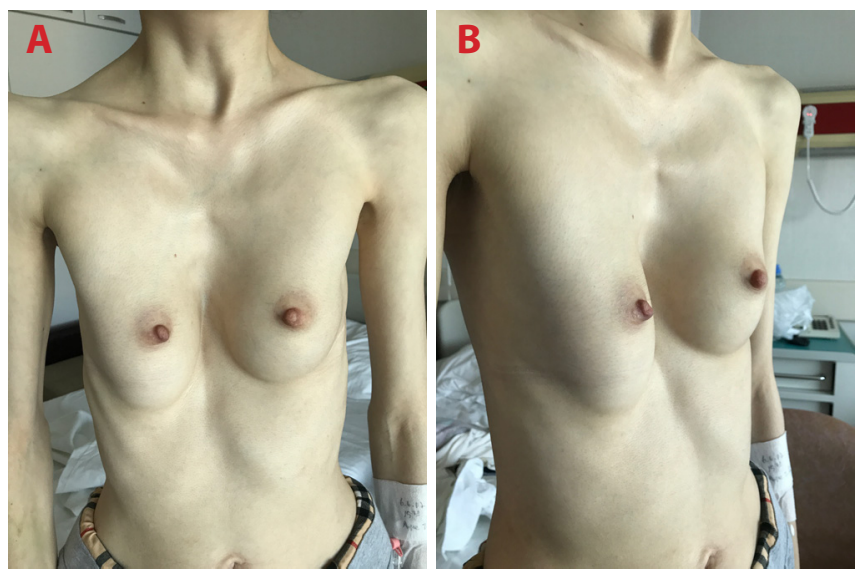

Fig. 1 - Marfanoid habitus and pectus excavatum. A) front view; B) side view.

atrium. Her ejection fraction was 35\%, left ventricle end-diastolic diameter was $72 \mathrm{~mm}$, and end-systolic diameter was $59 \mathrm{~mm}$. She also had a borderline ascending aortic aneurysm measuring 40 $\mathrm{mm}$ in diameter. Pulmonary function test demonstrated reduced forced vital capacity (FVC), 1.11 L (31.7\% of predicted), and reduced forced expiratory volume in $1^{\text {st }}$ second $\left(F_{E V}\right)$ ), $1.05 \mathrm{~L}$ (34.6\% of predicted). A contrast-enhanced computed tomography (CT) scan was performed to examine the mediastinal structures and alternative cannulation sites (Figure 2). Heart and great vessels were displaced to the left, and the right lung was enlarged and crossing the midline, anterior to the heart. The proxymal ascending aorta was $40 \mathrm{~mm}$ in diameter. Additionally, a chronic type $B$ aortic dissection was present. CT scan revealed that the ascending aorta and the superior and inferior venae cavae were suitable for cannulation.

\section{Therapeutic Intervention}

The patient received intensive chest physiotherapy before surgery to reduce postoperative pulmonary complications.

A vertical midline incision on skin, subcutaneous tissues, and pectoralis fascia was made over the sternum. Following elevation of pectoralis muscles from the anterior chest wall, a median

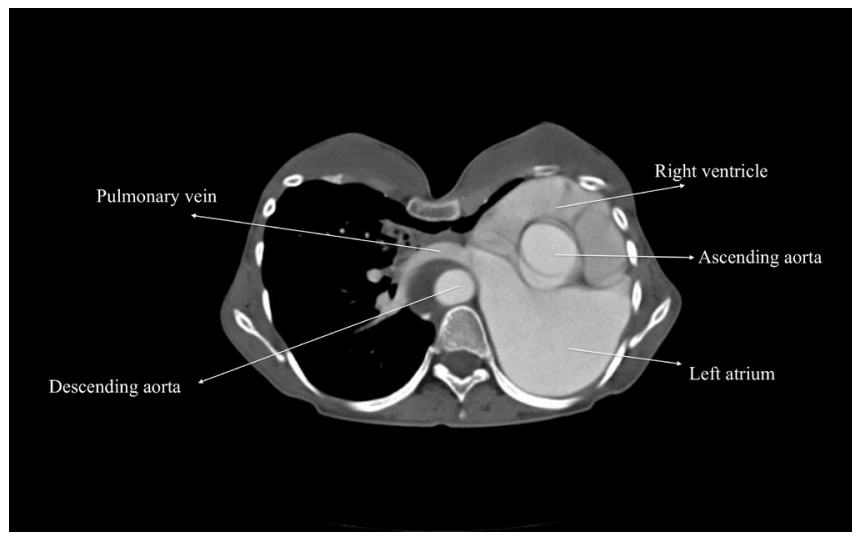

Fig. 2 - Contrast-enhanced computed tomography scan. sternotomy was performed. Costal cartilages of the $3^{\text {rd }}$ to $8^{\text {th }}$ ribs were removed. The right lung was retracted from the midline. Cardiopulmonary bypass (CPB) was initiated via ascending aortic and bicaval cannulation, and cardiac arrest was obtained. We did not use topical cardiac hypothermia to prevent phrenic nerve injury. Both atria were relatively easy to expose due to leftward shift and rotation of the heart. A mitral valve replacement and a tricuspid ring annuloplasty was performed using biatrial approach. CPB was terminated. A bar was placed behind the sternum and fixed to the pectoralis muscle fibers bilaterally. After completion of the Ravitch procedure, the sternum was closed. The patient was transferred to a dedicated cardiac surgery intensive care unit and she was successfully extubated at the postoperative $6^{\text {th }}$ hour. Her recovery was uneventful and she was discharged on postoperative day 9 (Figures $3 \mathrm{~A}$ and $\mathrm{B}$ ).
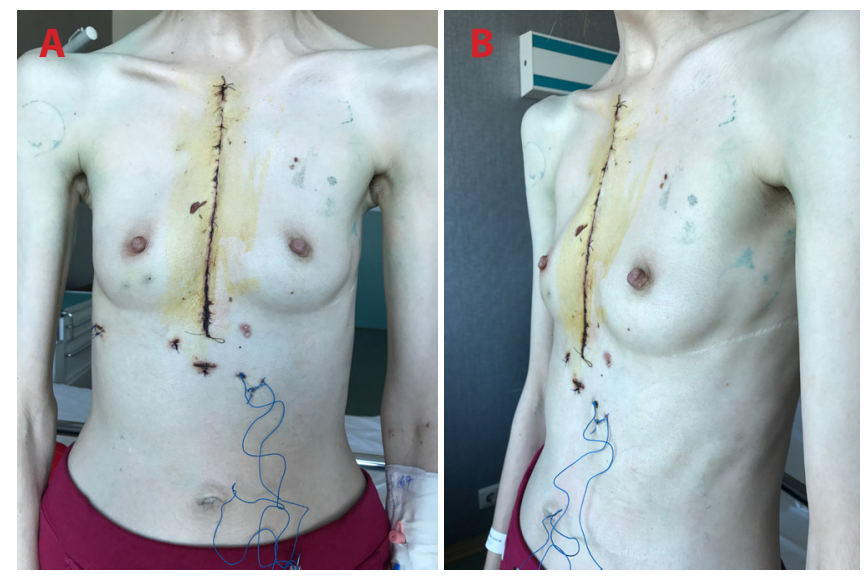

Fig. 3 - Early postoperative results. A) front view; B) side view.

\section{Follow-up and Outcomes}

The patient remains symptom-free 3 months after surgery and she is scheduled to have a bar removal 3 months later (Figures $4 \mathrm{~A}$ and $\mathrm{B}$ ).
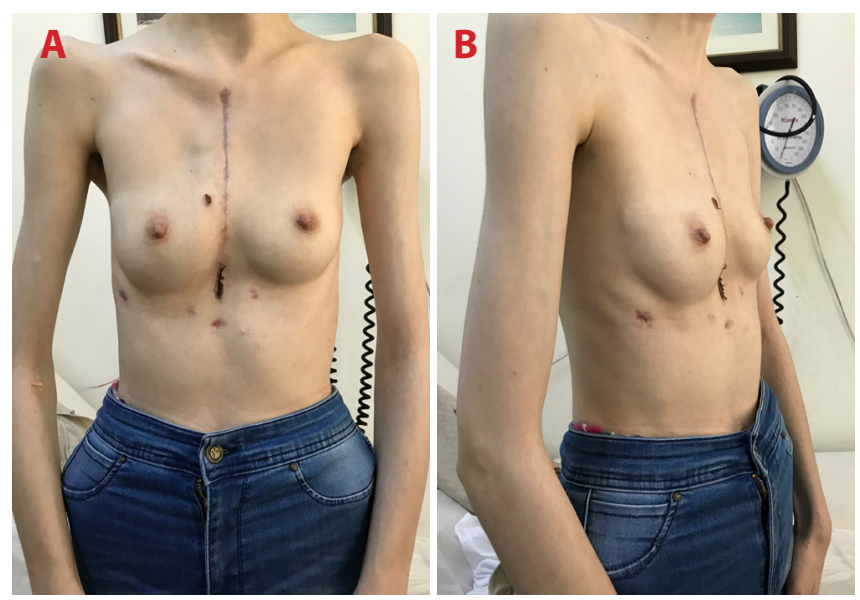

Fig. 4 - Late postoperative results. A) front view; B) side view. 
The Figure 5 presents a timeline of interventions and outcomes.

\section{A 24-year-old female with a 10-year history of a left pneumonectomy presented to our}

\section{clinic with dyspnea.}

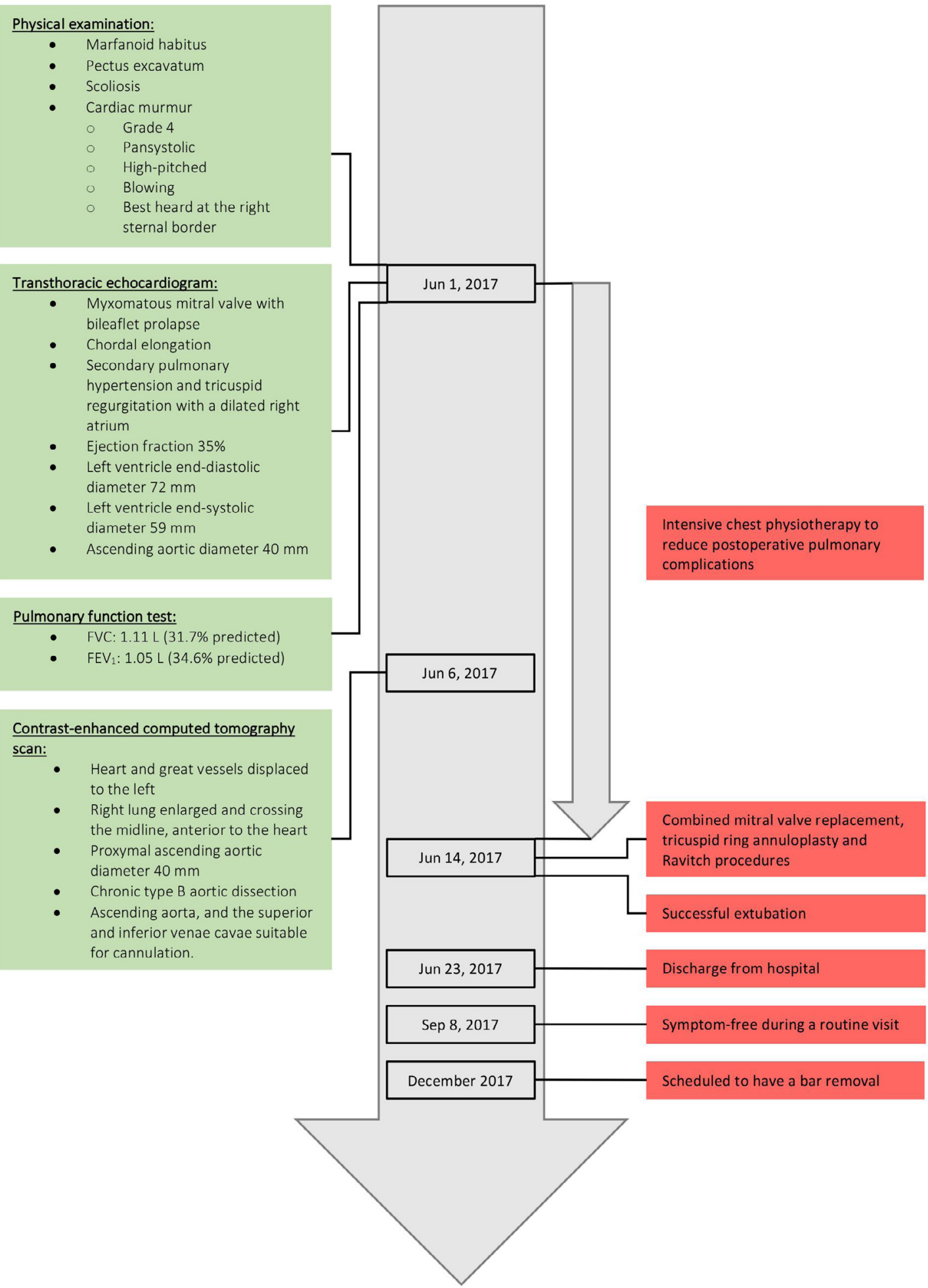

Fig. 5 - Timeline of interventions and outcomes.

$F E V_{1}=$ forced expiratory volume in $1^{\text {st }}$ second; $F V C=$ forced vital capacity 


\section{DISCUSSION}

After conducting a Medline search from 1966 to April 2018 using the search terms "pneumonectomy" and "open heart surgery" or "coronary artery bypass" or "mitral valve" or "aortic valve" or "revascularization", we identified 30 articles in English language ${ }^{[3-34]}$. A total of 42 cardiac operations were performed on 38 patients, including the current one (Table 1). The mean patient age was 65.2 years (range: $24-83$ years). Twenty-one (76.3\%) patients were male. There were 20 (47.6\%) isolated coronary artery bypass grafting (CABG) procedures, 18 (42.8\%) valvular procedures, and 4 (9.5\%) combined CABG and valvular procedures. Two of these operations were transapical aortic valve implantation procedures (patients 29 and 30) [26,27]. $^{27}$.

Fifteen (39.4\%) patients had a previous right pneumonectomy. The most common indication for pneumonectomy was cancer $(n=27,71 \%)$, followed by tuberculosis $(n=5,13.1 \%)$, trauma $(n=2$, $5.2 \%)$, bronchiectasis $(n=2,5.2 \%)$, scimitar syndrome $(n=1,2.6 \%)$, and unknown etiology $(n=1,2.6 \%)$. Preoperative FEV values were available for 28 patients and averaged $49 \%$ of predicted (range: $21-77 \%)$. Preoperative FVC values were available for 25 patients and averaged $49.2 \%$ of predicted (range: $27-70.3 \%$ ).

The preferred surgical incision was a median sternotomy in 26 (61.9\%) cases, a left thoracotomy in 9 (21.4\%) cases, a right thoracotomy in $6(14.2 \%)$ cases, and it was not specified in 1 (2.3\%) case. Patients 35 and 37 underwent surgery utilizing videoassisted right thoracotomy ${ }^{[32,34]}$. Among 24 CABG operations, a left internal thoracic artery was used as a bypass conduit in 7 (29.1\%) cases. The use of a right internal thoracic artery was not reported. Complete arterial revascularization was performed in 2 (8.3\%) cases. Among 20 isolated CABG operations, 7 (35\%) were carried out without the use of CPB.

Length of hospital stay data was available in 32 cases and averaged 12 days (range: 4-57 days). Postoperative complications were experienced after 11 (26.1\%) operations. The most common complication was atrial fibrillation $(n=5$, $11.9 \%)$, followed by respiratory failure requiring re-intubation $(n=4,9.5 \%)$, pneumothorax $(n=2,4.7 \%)$, pneumonia $(n=2,4.7 \%)$, and bleeding requiring re-exploration $(n=2,4.7 \%)$. Two (5.2\%) patients did not survive to discharge.

Previous pneumonectomy adds two major risks to cardiac operations: (1) there is an increased risk of postoperative pulmonary complications due to reduced lung capacity; (2) heart and great vessels are displaced and rotated, making surgical exposure more difficult.

Six months after pneumonectomy, FVC decreases by $36 \%$ and $\mathrm{FEV}_{1}$ by $34 \%$. These parameters do not significantly improve beyond 6 months ${ }^{[2]}$. Considering that the pulmonary function may deteriorate significantly after cardiac surgery even in patients who have normal preoperative respiratory function, previous pneumonectomy poses a great risk of postoperative pulmonary complications ${ }^{[35]}$. Hulzebos et al. ${ }^{[36]}$ found preoperative inspiratory muscle training to be effective in preventing postoperative pulmonary complications in high-risk patients undergoing elective CABG surgery. Conventional measures such as avoidance of phrenic nerve injury and fluid overload, early extubation, early mobilization, and postoperative chest physiotherapy should be utilized. Central venous line should be placed on the side of the pneumonectomy to avoid pneumothorax.

Considerable anatomical changes occur in long-term survivors after pneumonectomy. Smulders et al. ${ }^{[1]}$ evaluated the function and position of the heart using dynamic magnetic resonance imaging (MRI) in 15 patients who underwent pneumonectomy at least 5 years ago. They reported that although varying degrees of mediastinal shift occur in all patients, right-sided pneumonectomy is mostly associated with a lateral shift and only a minor rotation, whereas left-sided pneumonectomy leads to a greater degree of rotation ${ }^{[1]}$. Whether the patient had a left or right pneumonectomy, it affects the choice of surgical approach. For instance, in the case of a previous left pneumonectomy, it may be easier to bypass left-sided coronary arteries through a left thoracotomy, rather than a median sternotomy, and mitral and tricuspid valves may be inaccessible from the usual right thoracotomy. Stoller et al. ${ }^{[19]}$ reported difficult exposure of the mitral valve through a median sternotomy in a patient who underwent a left pneumonectomy 9 years ago. However, we found it relatively easy to perform a mitral valve surgery in a similar setting. Because long-term anatomical changes after pneumonectomy vary considerably among patients, preoperative CT and/or MRI should be performed to assess the exact locations of cardiac structures and cannulation sites $^{[37]}$. Decision of surgical approach should only be made after carefully examining the extent of the shift and the rotation of the cardiac structures.

Another subject that needs addressing is the concomitant pectus excavatum. Schmidt et al. ${ }^{[38]}$ advocate simultaneous correction of the pectus excavatum in patients requiring cardiac surgery. We resected deformed cartilages prior to sternotomy to improve surgical exposure as previously reported by SaccoCasamassima et al. ${ }^{[39]}$.

Cardiac operations on patients with previous pneumonectomy can be performed with a favourable outcome. Thorough preoperative evaluation with imaging studies to assess cardiac position and function and intensive respiratory physiotherapy are essential.

\section{Authors' roles \& responsibilities}

IK Substantial contributions to the conception or design of the work; or the acquisition, analysis, or interpretation of data for the work; drafting the work or revising it critically for important intellectual content; final approval of the version to be published

ACT Substantial contributions to the conception or design of the work; final approval of the version to be published

KO Substantial contributions to the conception or design of the work; final approval of the version to be published

YO Substantial contributions to the conception or design of the work; final approval of the version to be published

$A B$ Substantial contributions to the conception or design of the work; final approval of the version to be published

MY Substantial contributions to the conception or design of the work; final approval of the version to be published 


\begin{tabular}{|c|c|c|c|c|c|c|c|}
\hline & 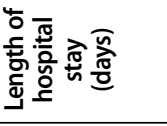 & $\infty$ & in & $=$ & $\simeq$ & $\wedge$ & $\wedge$ \\
\hline & 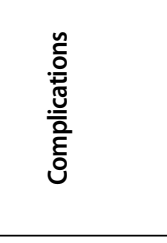 & $\frac{\tilde{\Sigma}}{2}$ & $\frac{\tilde{\Xi}}{2}$ & $\frac{\mathscr{g}}{\tilde{z}}$ & 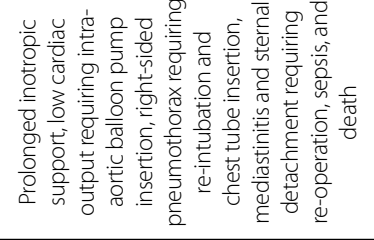 & $\frac{\tilde{\Sigma}}{2}$ & $\begin{array}{l}\mathscr{g} \\
\stackrel{0}{z}\end{array}$ \\
\hline & 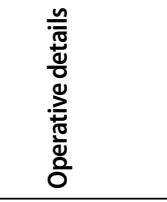 & 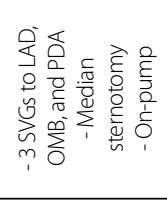 & 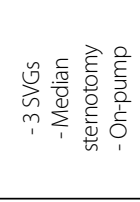 & 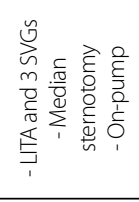 & 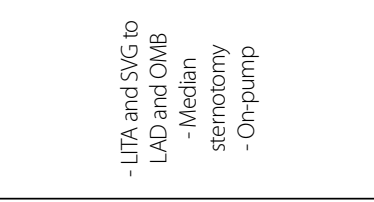 & 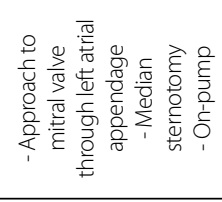 & 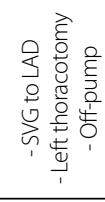 \\
\hline & 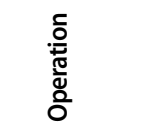 & 浐 & 岤 & 岁 & 兽 & 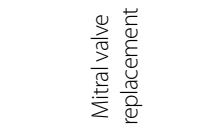 & 吕 \\
\hline 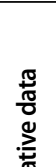 & 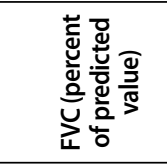 & $\tilde{m}$ & 出 & in & $\stackrel{m}{\circ}$ & $\frac{\mathbb{T}}{z}$ & $\stackrel{\mathbb{z}}{z}$ \\
\hline 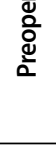 & 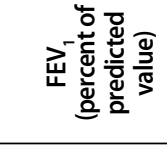 & $\bar{\sim}$ & 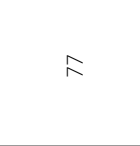 & ケ & $\stackrel{m}{\circ}$ & $\frac{\mathbb{T}}{z}$ & $\frac{1}{z}$ \\
\hline & 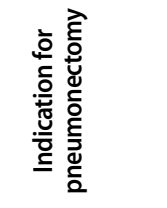 & 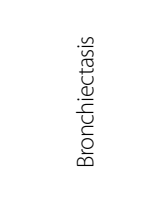 & 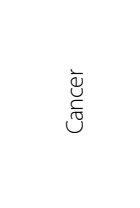 & 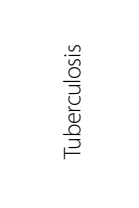 & $\begin{array}{l}\overline{\bar{\Xi}} \\
\text { 芯 }\end{array}$ & $\begin{array}{l}\overline{\bar{\Xi}} \\
\text { 芯 }\end{array}$ & 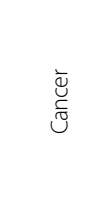 \\
\hline & 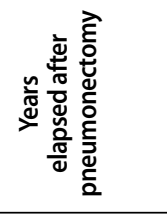 & $f$ & $m$ & q & $\stackrel{\sim}{ }$ & $\stackrel{\circ}{\circ}$ & $\stackrel{\rho}{-}$ \\
\hline & 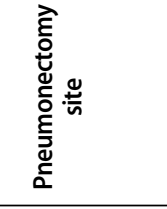 & $\frac{\vec{t}}{\frac{\vec{v}}{x}}$ & $\stackrel{\mathbb{J}}{\Delta}$ & $\frac{\pi}{\Delta}$ & $\stackrel{\square}{ \pm}$ & $\begin{array}{l}\frac{\vec{t}}{\bar{\sigma}} \\
\frac{9}{\alpha}\end{array}$ & $\stackrel{\square}{ \pm}$ \\
\hline & 学 & $\bar{\sigma}$ & 6 & 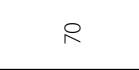 & గి & \& & $尺$ \\
\hline & $\stackrel{㐅}{\circledR}$ & $\Sigma$ & $\Sigma$ & \llcorner & $\Sigma$ & $\Sigma$ & 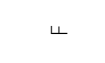 \\
\hline & 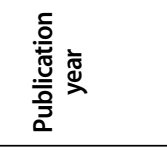 & $\stackrel{+}{\circ}$ & 壵 & $\stackrel{\text { హ్ }}{\sigma}$ & $\begin{array}{l}\stackrel{2}{\alpha} \\
\alpha\end{array}$ & $\begin{array}{l}\stackrel{\sim}{\sigma} \\
\sigma\end{array}$ & $\begin{array}{l}\infty \\
\stackrel{2}{\sigma}\end{array}$ \\
\hline & 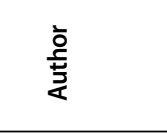 & 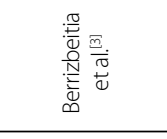 & 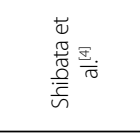 & 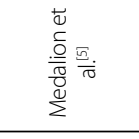 & 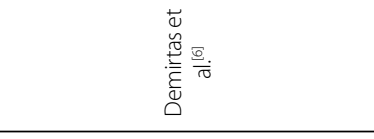 & 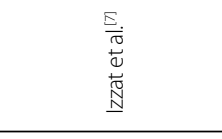 & 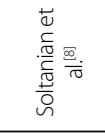 \\
\hline & 蒙 & - & $\sim$ & $m$ & ナ & in & 0 \\
\hline
\end{tabular}




\begin{tabular}{|c|c|c|c|c|c|c|c|c|c|}
\hline 0 & $\stackrel{\infty}{\alpha}$ & $\sigma$ & $\simeq$ & i & 0 & $\wedge$ & in & 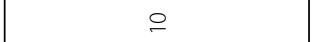 & $\infty$ \\
\hline 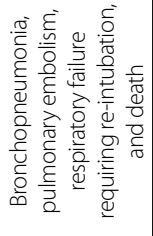 & 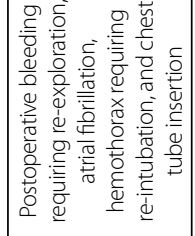 & $\begin{array}{l}\stackrel{0}{\tilde{\Sigma}} \\
\frac{1}{2}\end{array}$ & 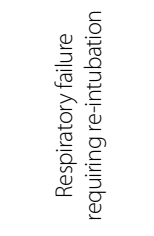 & 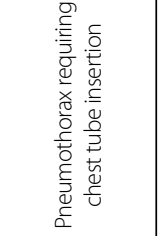 & $\begin{array}{l}\stackrel{\mathscr{\nu}}{\frac{\partial}{2}} \\
\end{array}$ & 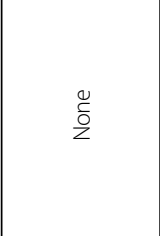 & $\frac{\mathscr{c}}{2}$ & $\begin{array}{l}\stackrel{0}{\tilde{O}} \\
\frac{1}{2}\end{array}$ & $\begin{array}{l}\stackrel{0}{\frac{\sigma}{2}} \\
\end{array}$ \\
\hline 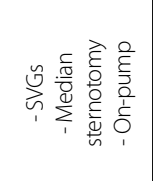 & 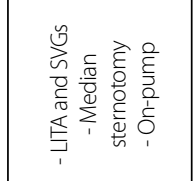 & 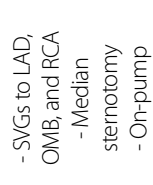 & 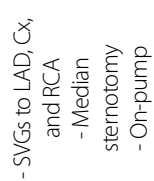 & 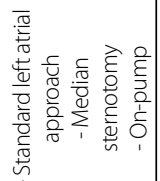 & 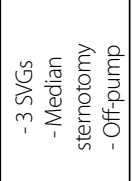 & 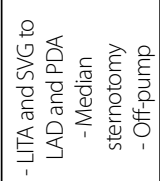 & 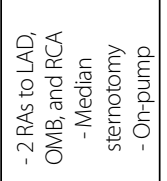 & 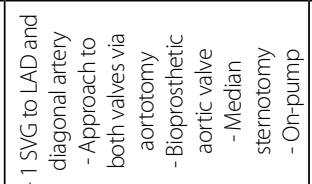 & 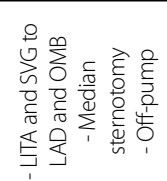 \\
\hline 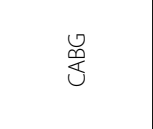 & 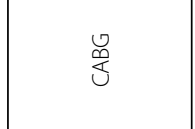 & 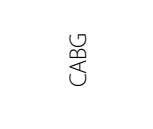 & 过 & 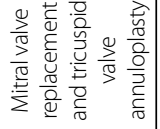 & 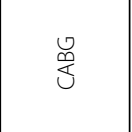 & 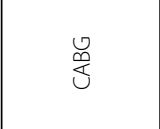 & 递 & 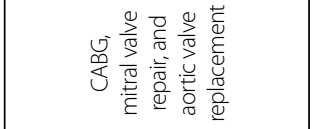 & 通 \\
\hline 8 & $\stackrel{\infty}{\leftrightarrow}$ & F & $\frac{\bar{z}}{z}$ & F & $\bar{\lambda}$ & $\stackrel{\frac{J}{z}}{z}$ & भ & $\frac{\pi}{z}$ & in \\
\hline in & in & in & $\frac{z}{z}$ & $\stackrel{\infty}{\infty}$ & $\stackrel{\infty}{\sim}$ & $\frac{\mathbb{z}}{z}$ & ケ & f & in \\
\hline 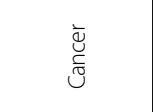 & 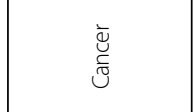 & 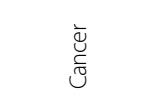 & 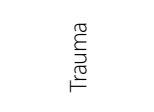 & 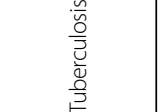 & 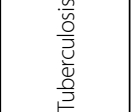 & 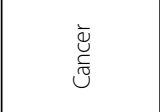 & 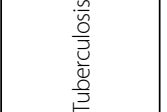 & 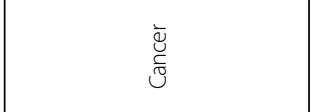 & 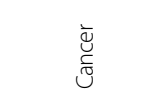 \\
\hline$\stackrel{n}{\simeq}$ & $\approx$ & م̂. & $\bullet$ & in & in & 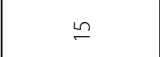 & $=$ & $\bar{\lambda}$ & $m$ \\
\hline$\stackrel{\mathbb{E}}{\Delta}$ & $\stackrel{ \pm}{\Delta}$ & 蒙 & 薆 & 莖 & $\begin{array}{l}\text { 蒿 } \\
\text { 竞 }\end{array}$ & $\stackrel{\frac{\pi}{G}}{ }$ & 薆 & $\stackrel{\Delta}{\Delta}$ & 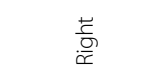 \\
\hline$\ddot{\infty}$ & 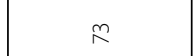 & $\stackrel{\infty}{\leftrightarrow}$ & J & $\tilde{b}$ & $\Sigma$ & 尺 & in & $\infty$ & $\stackrel{\infty}{\leftrightarrow}$ \\
\hline$\Sigma$ & $\Sigma$ & $\Sigma$ & $\Sigma$ & 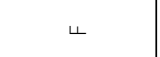 & 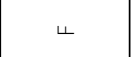 & $\Sigma$ & $\Sigma$ & $\Sigma$ & $\Sigma$ \\
\hline & ষ্ণ & $\bar{\delta}$ & $\bar{\delta}$ & ্ֻণ & & ర్లి & ఫ্ণ & 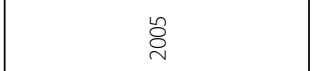 & ఫ্రి \\
\hline & 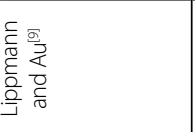 & 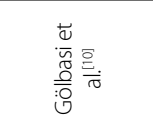 & 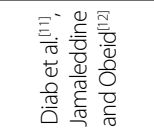 & 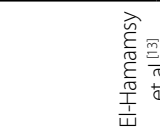 & & 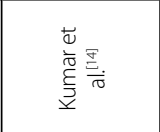 & 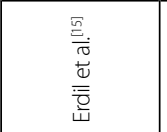 & 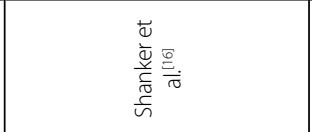 & 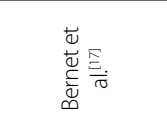 \\
\hline$\wedge$ & $\infty$ & $a$ & 으 & $=$ & $\simeq$ & $\underline{m}$ & \pm & 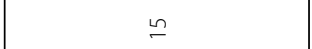 & 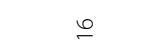 \\
\hline
\end{tabular}




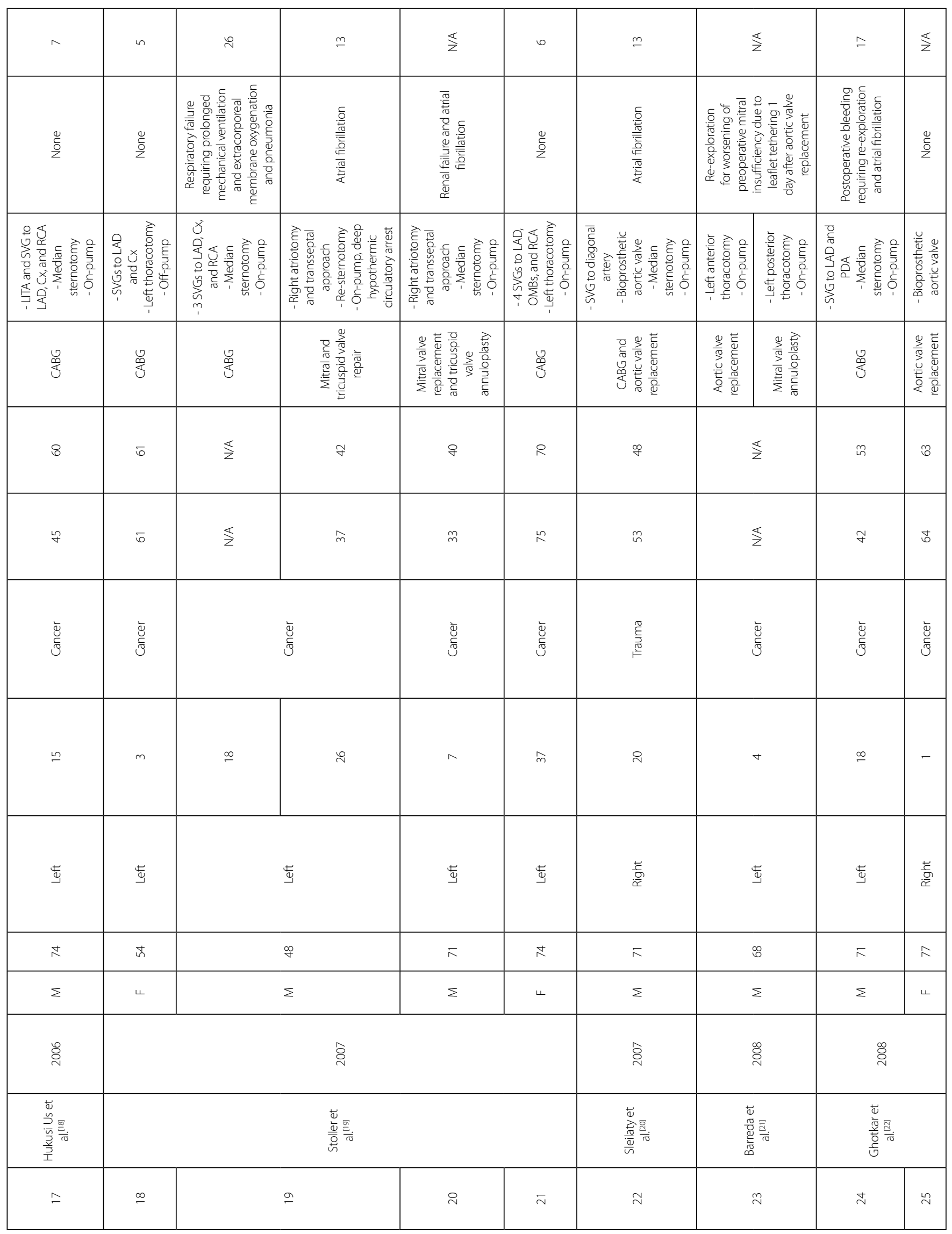




\begin{tabular}{|c|c|c|c|c|c|c|c|}
\hline$a$ & $\lambda$ & in & $\frac{\pi}{z}$ & 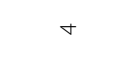 & $\frac{\pi}{z}$ & 6 & $\frac{\pi}{z}$ \\
\hline 䓂 & 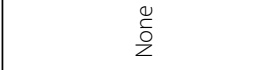 & $\begin{array}{l}\mathscr{0} \\
\frac{0}{2}\end{array}$ & $\begin{array}{l}\frac{0}{0} \\
\frac{0}{z}\end{array}$ & $\begin{array}{l}\stackrel{0}{\tilde{o}} \\
z\end{array}$ & 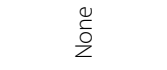 & $\begin{array}{l}0 \\
\text { ¿े }\end{array}$ & $\begin{array}{l}0 \\
\frac{0}{2} \\
\end{array}$ \\
\hline 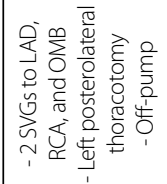 & 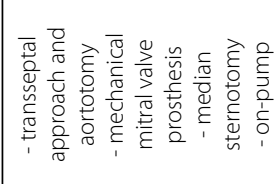 & 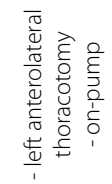 & 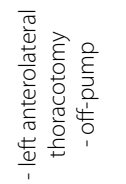 & 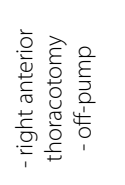 & 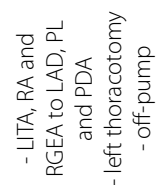 & 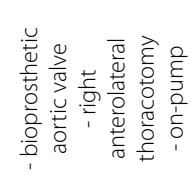 & 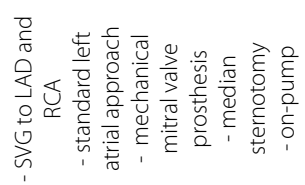 \\
\hline 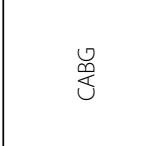 & 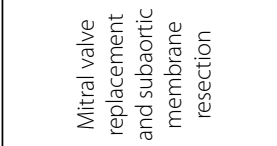 & 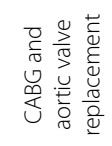 & 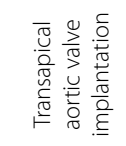 & 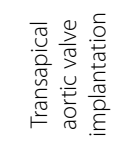 & 浐 & 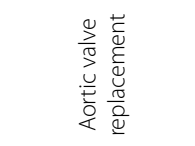 & 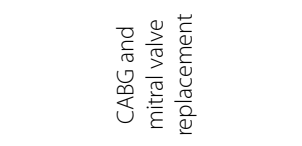 \\
\hline$\stackrel{m}{p}$ & in & $\frac{\mathbb{s}}{z}$ & $\stackrel{\mathbb{z}}{z}$ & $\frac{\mathbb{s}}{z}$ & 我 & $\stackrel{\infty}{n}$ & $\frac{\mathbb{1}}{z}$ \\
\hline$\frac{9}{6}$ & \& & $\stackrel{\infty}{f}$ & $\stackrel{\pi}{z}$ & $g$ & $\begin{array}{l}\infty \\
\tilde{\beta}\end{array}$ & $\stackrel{i}{\circ}$ & 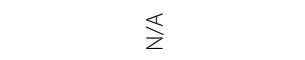 \\
\hline 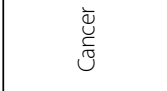 & $\stackrel{ \pm}{z}$ & $\begin{array}{l}\overline{\bar{\Xi}} \\
\text { 厄. }\end{array}$ & $\begin{array}{l}\overline{\bar{\Xi}} \\
\text { ভ্ }\end{array}$ & $\begin{array}{l}\overline{\bar{\Xi}} \\
\text { ভ্ }\end{array}$ & $\begin{array}{l}\overline{\bar{\Xi}} \\
\text { 芯 }\end{array}$ & $\begin{array}{l}\overline{\bar{u}} \\
\text { 芯 }\end{array}$ & $\begin{array}{l}\bar{\Xi} \\
\stackrel{\bar{J}}{u}\end{array}$ \\
\hline$\wedge$ & $\infty$ & $\infty$ & $\infty$ & $\stackrel{\infty}{\simeq}$ & i & $\infty$ & $\underline{m}$ \\
\hline$\stackrel{\mathbb{U}}{\mathbb{E}}$ & $\stackrel{\square}{\Phi}$ & $\stackrel{ \pm}{ \pm}$ & $\Phi$ & 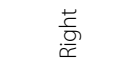 & $\stackrel{\mathbb{U}}{\mathbb{U}}$ & $\begin{array}{l}\text { 蒿 } \\
\text { 至 }\end{array}$ & $\stackrel{\mathbb{Q}}{\Delta}$ \\
\hline in & 号 & $\infty$ & J & $\hat{\sigma}$ & $\infty$ & $\infty$ & $\approx$ \\
\hline$\Sigma$ & $\Sigma$ & $\Sigma$ & $\Sigma$ & 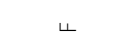 & $\Sigma$ & $\Sigma$ & $\Sigma$ \\
\hline$\stackrel{\infty}{\stackrel{\infty}{~}}$ & $\stackrel{\circ}{\circ}$ & $\stackrel{\circ}{\grave{2}}$ & $\bar{i}$ & $\overline{\bar{N}}$ & $\bar{i}$ & $\grave{i}_{\bar{N}}$ & $\stackrel{m}{i}^{m}$ \\
\hline 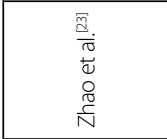 & 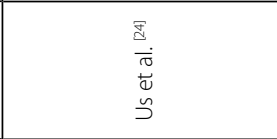 & 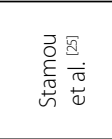 & 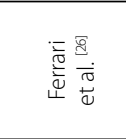 & $\begin{array}{l}\frac{a}{a} \\
\frac{\pi}{\pi} \\
\frac{\pi}{\pi} \\
\frac{\pi}{\pi} \\
\frac{\pi}{\pi}\end{array}$ & 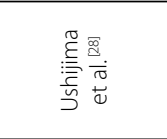 & 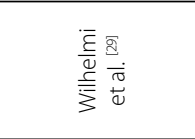 & 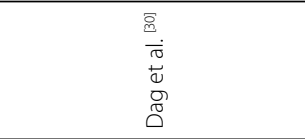 \\
\hline$\stackrel{\sim}{\sim}$ & $\bar{\lambda}$ & $\stackrel{\infty}{\sim}$ & $\stackrel{\sim}{.}$ & m & $\bar{m}$ & $\tilde{m}$ & $m$ \\
\hline
\end{tabular}




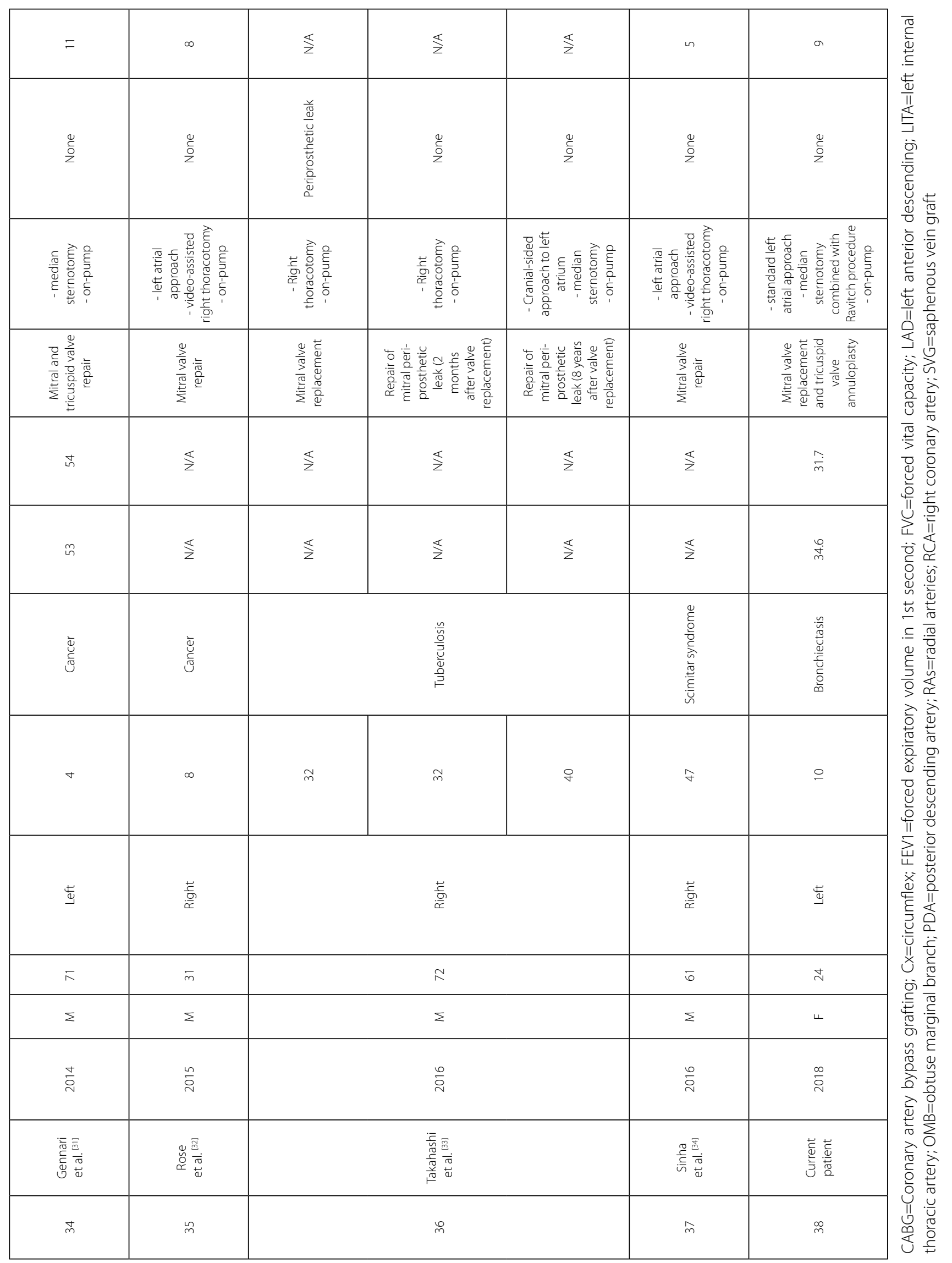




\section{REFERENCES}

1. Smulders SA, Holverda S, Vonk-Noordegraaf A, van den Bosch HC, Post JC, Marcus JT, et al. Cardiac function and position more than 5 years after pneumonectomy. Ann Thorac Surg. 2007;83(6):1986-92.

2. Bolliger CT, Jordan P, Solèr M, Stulz P, Tamm M, Wyser C, et al. Pulmonary function and exercise capacity after lung resection. Eur Respir J. 1996;9(3):415-21.

3. Berrizbeitia LD, Anderson WA, Laub GW, McGrath LB. Coronary artery bypass grafting after pneumonectomy. Ann Thorac Surg. 1994;58(5):1538-40.

4. Shibata T, Suehiro S, Kimura E, Nishizawa H, Minamimura H, Kinoshita H. Coronary artery bypass grafting 13 years after pneumonectomy. Nihon Kyobu Geka Gakkai Zasshi. 1994;42(7):1105-7.

5. Medalion B, Elami A, Milgalter E, Merin G. Open heart operation after pneumonectomy. Ann Thorac Surg. 1994;58(3):882-4.

6. Demirtas MM, Akar H, Kaplan M, Dagsali S. Coronary artery bypass operation after pneumonectomy. Ann Thorac Surg. 1995;60(1):232-3.

7. Izzat MB, Regragui IA, Angelini GD. Mitral valve replacement after previous right pneumonectomy. Ann Thorac Surg. 1995;59(1):222-4.

8. Soltanian H, Sanders JH Jr, Robb JC, Marrin CA. Hybrid myocardial revascularization after previous left pneumonectomy. Ann Thorac Surg. 1998;65(1):259-60.

9. Lippmann M, Au J. Coronary artery bypass surgery after previous pneumonectomy: two case reports. Scand Cardiovasc J. 2000;34(5):541-2.

10. Gölbasi I, Türkay C, Sahin N, Oz N, Akbulut E, Gülmez H, et al. Coronary artery bypass grafting nine months after pneumonectomy. Tex Heart Inst J. 2001;28(2):146-8.

11. Diab KA, Khatib MF, Obeid M, Jamaleddine GW. Coronary artery bypass grafting after pneumonectomy. Eur J Cardiothorac Surg. 2001;19(3):362-4.

12. Jamaleddine GW, Obeid M. Reply to Pezzella. Eur J Cardiothorac Surg. 2001;20:1274.

13. El-Hamamsy I, Stevens LM, Perrault LP, Carrier M. Right pneumonectomy and thoracoplasty followed by coronary artery bypass grafting and mitral valve replacement. J Thorac Cardiovasc Surg. 2003;125(1):215-6.

14. Kumar P, Swift SJ, AthanasiouT, Nelson JS, Glenville B. CABG 15-years after left pneumonectomy: feasibility of off-pump approach. Cardiovasc Surg. 2003;11(4):305-7.

15. Erdil N, Nisanoglu V, Toprak HI, Erdil FA, Kuzucu A, Battaloglu B. Arterial myocardial revascularization using bilateral radial artery 17 years after right pneumonectomy. Tex Heart Inst J. 2004;31(1):96-8.

16. Shanker VR, Yadav S, Hodge AJ. Coronary artery bypass grafting with valvular heart surgery after pneumonectomy. ANZ J Surg. 2005;75(12):88-90.

17. Bernet FH, Reineke DC, Grapow MT, Zerkowski HR. OPCAB surgery after right pneumonectomy. J Card Surg. 2006;21(1):92-3.

18. Hulusi Us M, Arslan Y, Ozbek C, Basaran M, Yidiz Y, Ogus T, et al. Coronary artery bypass grafting after left pneumonectomy. J Cardiothorac Vasc Anesth. 2006;20(5):709-11.

19. Stoller JK, Blackstone E, Petterson G, Mihaljevic T. Coronary artery bypass graft and/or valvular operations following prior pneumonectomy: report of four new patients and review of the literature. Chest. 2007;132(1):295-301.

20. Sleilaty G, Yazigi A, El Asmar B, Hajj-Chahine J, Nakad J, Madi-Jebara S, et al. Combined coronary surgery and aortic valve replacement after previous right pneumonectomy. J Med Liban. 2007;55(2):101-3.

21. Barreda T, Laali M, Dorent R, Acar C. Left thoracotomy for aortic and mitral valve surgery in a case of mediastinal displacement due to pneumonectomy. J Heart Valve Dis. 2008;17(2):239-42.
22. Ghotkar SV, Aerra V, Mediratta N. Cardiac surgery in patients with previous pneumonectomy. J Cardiothorac Surg. 2008;3:11.

23. Zhao $B Q$, Chen RK, Song JP. Coronary artery bypass grafting after pneumonectomy. Tex Heart Inst J. 2008;35(4):470-1.

24. Us MH, Ugurlucan M, Basaran M, Selimoglu O, Kocailik A. Mitral valve replacement and subaortic membrane resection following pneumonectomy. Case Rep Med. 2010;2010:480703.

25. Stamou SC, Murphy MC, Kouchoukos NT. Aortic valve replacement and coronary artery bypass via left anterior thoracotomy after previous left pneumonectomy. J Thorac Cardiovasc Surg. 2010;140(3):719-20.

26. Ferrari E, Sulzer C, Marcucci C, Qanadly SD, Locca D, Berdajs D, et al. Transapical aortic valve implantation following left pneumonectomy. J Card Surg. 2011;26(1):28-30.

27. Raja Y, Mascaro J, Doshi SN. Successful implantation of the Edwards Sapien THV via direct aortic access in a patient with previous pneumonectomy and no other access. Catheter Cardiovasc Interv. 2011;78(7):1008-12.

28. Ushijima T, Kikuchi Y, Ikeda C, Takata M, Yamamoto Y, Watanabe G. Totally arterial off-pump coronary artery bypass grafting after pneumonectomy. Ann Thorac Cardiovasc Surg. 2011;17(3):320-2.

29. Wilhelmi M, Rodt T, Ismail I, Haverich A. Aortic valve replacement via right anterolateral thoracotomy in the case of a patient with extreme mediastinal right-shift following pneumonectomy. J Cardiothorac Surg. 2013;8:20.

30. Dag O, Kaygin MA, Arslan U, Kiymaz A, Kahraman N, Erkut B. Mitral valve and coronary artery bypass surgeries 13 years after pneumonectomy for lung cancer. Cardiovasc J Afr. 2013;24(8):e1-4.

31. Gennari M, Kassem S, Teruzzi G, Agrifoglio M. Coronary artery disease associated with severe mitral and tricuspid valve regurgitation after left pneumonectomy: report of a successful hybrid procedure. Interact Cardiovasc Thorac Surg. 2014;19(2):318-20.

32. Rose D, Liew CK, Zacharias J. Mitral valve repair after a right pneumonectomy: a minimally invasive approach. Interact Cardiovasc Thorac Surg. 2015;21(4):551-3.

33. Takahashi Y, Shibata T, Sasaki Y, Kato Y, Motoki M, Morisaki A, et al. A cranial-sided approach for repeated mitral periprosthetic leak after right pneumonectomy. Ann Thorac Surg. 2016;101(3):1174-6.

34. Sinha S, Morgan-Hughes N, O'Toole L, Hunter S. Minimal access mitral valve repair in a patient with a right pneumonectomy for Scimitar syndrome. Interact Cardiovasc Thorac Surg. 2016;22(6):851-3.

35. Westerdahl E, Lindmark B, Bryngelsson I, Tenling A. Pulmonary function 4 months after coronary artery bypass graft surgery. Respir Med. 2003;97(4):317-22.

36. Hulzebos EH, Helders PJ, Favié NJ, De Bie RA, Brutel de la Riviere A, Van Meeteren NL. Preoperative intensive inspiratory muscle training to prevent postoperative pulmonary complications in high-risk patients undergoing CABG surgery: a randomized clinical trial. JAMA. 2006;296(15):1851-7.

37. Kopec SE, Irwin RS, Umali-Torres CB, Balikian JP, Conlan AA. The postpneumonectomy state. Chest. 1998;114(4):1158-84.

38. Schmidt J, Redwan B, KoesekV, Aebert H, TjanTD, Martens S, et al. Pectus excavatum and cardiac surgery: simultaneous correction advocated. Thorac Cardiovasc Surg. 2014;62(3):238-44.

39. Sacco-Casamassima MG, Wong LL, Papandria D, Abdullah F, Vricella $L A$, Cameron DE, et al. Modified Nuss procedure in concurrent repair of pectus excavatum and open heart surgery. Ann Thorac Surg. 2013;95(3):1043-9. 